\title{
Utilização de Redes de Confiança para Detecção de Anomalias em RSSF
}

\author{
Beatriz de A. Campos ${ }^{1}$, Claudio M. de Farias ${ }^{1}$, Luiz Fernando Rust ${ }^{12}$ \\ ${ }^{1}$ Núcleo de Computação Eletrônica (NCE) - Universidade Federal do Rio de Janeiro (UFRJ) \\ Rio de Janeiro, RJ - Brasil \\ ${ }^{2}$ Instituto Nacional de Metrologia, Qualidade e Tecnologia (INMETRO) \\ Rio de Janeiro, RJ - Brasil \\ beatrizac@labnet.nce.ufrj.br, claudiofarias@nce.ufrj.br, lfrusteinmetro.gov.br
}

\begin{abstract}
This article presents a proposal for the use of trust networks to improve anomaly detection in Wireless Sensor Networks (WSN). The motivation to using WSNs is due to its low computing resources. This scenario is used as a motivating scenario for all smart environments.
\end{abstract}

Resumo. Este artigo apresenta uma proposta para a utilização de redes de confiança visando a melhoria do processo de detecção de anomalias em redes de sensores sem fio (RSSF). A motivação para utilizar RSSF é baseada no seu baixo poder computacional. Este cenário é utilizado como um cernário motivacional para todos os ambientes inteligentes.

\section{Introdução}

Redes de sensores sem fio (RSSF) são redes compostas de nós, geralmente com baixo poder de processamento e disposição energética moderada [Gubbi et al. 2013], que trabalham de forma descentralizada se comunicando através de uma rede não cabeada. Os sensores presentes nas RSSF são responsáveis por coletar os dados de ambientes, máquinas ou de humanos e enviá-los para servidores ou outros nós da rede, com maior poder computacional. O nó receptor dos dados coletados pelos nós sensores deve ser capaz de receber e dispor os dados recebidos para o usuário, afim de que ele tenha mais informações sobre o ambiente monitorado, ou enviar estes dados para o próximo nó da rede.

Além de erros relativos a problemas físicos no nó, as RSSF também são passíveis de ataques maliciosos como qualquer outra [Sinha et al. 2017, Kaushal and Kaur 2015]. Por utilizarem a rede sem fio os nós sensores estão suscetíveis a interceptação ou a sofrer interferência no sinal, gerada por atacantes [Sinha et al. 2017]. Os nós também podem sucumbir com ataques de negação de serviço (Denial of Service, DoS) que além impedir que o nó sensor execute suas tarefas também podem exaurir seus recursos energéticos, que podem ser limitados [Sinha et al. 2017, Kaushal and Kaur 2015]. Ataques bem sucedidos em controlar os nós, podem afetar a integridade dos dados enviados por ele [Sinha et al. 2017, Kaushal and Kaur 2015] e, desta forma, influenciar na observação do ambiente a ser monitorado. Outro aspecto que também deve ser observado é se o nó demonstra algum comportamento fraudulento, de forma a mascarar os dados reais [de Souza et al. 2017].

Sabendo dos possíveis problemas que permeiam uma rede, sejam eles quais forem, são apresentadas na literatura formas de identificá-los [Ahmed et al. 2016, 
Xie et al. 2011, Zhang et al. 2010] e este processo chama-se Detecção de Anomalias (DA). Anomalias são observações que são distintas dos outros dados coletados [Zhang et al. 2010] ou que fogem dos limites previamente determinados para coleta [Ahmed et al. 2016]. Anomalias que venham a afetar os nós de uma RSSF, influenciam na confiança dos dados obtidos por toda rede. Embora confiança seja um termo que possui certa subjetividade, no contexto de RSSF, é possível interpretá-lo como algo mensurável. Disponibilidade dos nós, qualidade de sinal e consumo energético são alguns dos meios de quantificar a confiança nos nós de acordo com estas características [Guo et al. 2017]. Se um nó não possui anomalias nestes parâmetros então pode ser considerado um nó confiável de acordo com estas métricas.

O termo "redes ou cadeias de confiança" (RC) é utilizado para exprimir relações entre duas partes, onde esta relação é afetada por eventos positivos ou negativos gerados por uma das partes [Jøsang et al. 2006, Victor et al. 2011]. Eventos considerados positivos reforçam a competência de uma das partes em realizar ações, eventos negativos fazem o oposto. Quanto maior o número de eventos positivos, maior a confiança que uma das partes possui na outra e vice-versa. São considerados eventos positivos o comportamento esperado e eventos negativos o comportamento anômalo. Ressalta-se que recentemente RC é um método que está sendo utilizado para atestar a confiança entre os nós neste tipo de rede [Dhulipala and Karthik 2017, Guo et al. 2017]. Ressalta-se que o termo "confiança" empregado neste contexto se refere ao funcionamento esperado (não anômalo) de um nó, de acordo com as funções que ele possua e em termos de consumo de energia, envio de mensagens, tempo entre medições, etc.

Segundo autores em [Dhulipala and Karthik 2017], o gerenciamento de confiança (GC) é um método utilizado para detectar falhas, ataques maliciosos e direcionar o roteamento de pacotes a partir de uma RC em funcionamento na rede. É possível traçar um paralelo entre o GC de uma rede e DA, visto que ambas as técnicas visam encontrar pontos da rede que não estejam funcionando de acordo com o esperado. Sabendo que o GC pode utilizar diversos parâmetros (como os citados anteriormente) para definir o grau de confiança de um nó, em vez de apenas classificar-lo como anômalo ou não. Neste caso, o tipo de anomalia que é detectada, seja ela de caráter físico ou lógico, é o que irá influenciar no grau de confiança que se tem em um determinado nó.

Existem diversas formas de calcular a confiança entre os nós de uma rede. Como a confiança depende do comportamento pretérito do nó, é desejável que eventos passados possam ser expressos de alguma forma. Uma maneira de manter o histórico, seria armazenar os dados sobre os sensores em uma tabela nos nós vizinhos. Porém em uma RSSF onde a capacidade de armazenamento dos nós é limitada, esta é uma opção pouco atraente devido ao seu custo de armazenamento associado. Técnicas de agregação do comportamento pretérito afim de quantificar numericamente a confiança em um nó são utilizadas para evitar a solução anteriormente citada [Guo et al. 2017].

Neste contexto, pode-se observar a Lógica Subjetiva (LS), que é um tipo de lógica que utiliza probabilidade para calcular o grau de certeza ou crença em determinado indivíduo ou na ocorrência de um evento. Um atrativo desta técnica é sua capacidade de agregar os valores de confiança, de forma que valores antigos possam ser agrupados com os novos. Isto faz com que, a informação acerca de anomalias possa ser expressada em um único valor [Jøsang 2001], o que é mais agradável ao cenário de RSSF. 
Em [Khan and Herrmann 2017] é apresentado um sistema de detecção de intrusão para IoT, que utiliza confiança para identificar diferentes tipos de ataque. No trabalho, buscaram analisar parâmetros relacionados aos ataques de sinkhole, selective-forwarding e version number, relacionados ao protocolo RPL (Routing Protocol for Low power and Lossy networks). De forma distinta do trabalho presente em [Khan and Herrmann 2017], a proposta aqui apresentada não foca em ataques de acordo com o protocolo de comunicação utilizado. O objetivo desta pesquisa é apresentar um algoritmo capaz de identificar o grau de certeza (confiança) dos dados obtidos pelos nós de uma RSSF e do próprio nó, verificando se estes dados são anômalos ou não. Esta medição é realizada através dos parâmetros de tempo entre troca de mensagens, consumo de energia do nó e dados coletados pelo nó. A abordagem utiliza Redes de Confiança para determinar a confiabilidade nos dados provenientes de um determinado nó, através do grau de confiança associado a ele. $\mathrm{O}$ decaimento do grau de confiança de um determinado nó da rede, neste caso, irá sinalizar que há uma anomalia no nó.

O restante do artigo esta disposto da seguinte forma: na seção 2 é discutido o conceito de redes de confiança e formas de agregação da mesma; na seção 3 é explicado o modelo de utilização proposto; na seção 4 é apresentada a conclusão do trabalho.

\section{Redes de Confiança}

A confiança pode ser definida como a capacidade de um elemento computacional qualquer executar de forma esperada (confiável) seu papel na rede. O grau de confiança em um nó da rede é proveniente da avaliação de diversos aspectos deste elemento. Exemplos de aspectos que podem ser avaliados são: nível de energia utilizado; dados provenientes do nó; excesso ou ausência de troca de mensagens; disponibilidade; nível de processamento. Caso um ou mais destes aspectos venham a ser considerados anômalos, o grau de confiança no nó é reduzido.

Assumindo o conceito de confiança previamente definido, pode-se entender que redes de confiança $(\mathrm{RC})$ são utilizadas para exprimir relações entre duas partes, onde esta relação é influenciada por eventos positivos ou negativos gerados por uma das partes [Jøsang et al. 2006, Victor et al. 2011]. Quanto maior o número de eventos positivos, maior a confiança que uma das partes possui na outra e vice-versa.

Os autores em [Guo et al. 2017], elaboraram uma classificação para os diferentes atributos de uma RC. Na categoria "agregação de confiança" estão as técnicas utilizadas para agrupar a confiança em nós, de acordo com comportamento apresentado por eles, sendo este anômalo ou não. Estes métodos geram um valor de confiança para os dados recebidos e são capazes de agrupar dois valores diferentes de confiança sobre uma determinada entidade. Com o aumento do número de eventos, o resultado da junção de dois valores de confiança faz com que o nó que envia os dados seja denominado mais ou menos confiável. Os métodos apresentados não mantém uma tabela contendo ações passadas do nó. O resultado positivo ou negativo das ações dos nós é representado de forma agregada no valor da confiança computada através destes métodos.

Um dos métodos que pode ser utilizado para calcular RC é a Lógica Subjetiva (LS). A LS é um tipo de lógica probabilística, que utiliza quatro parâmetros para calcular a confiança em que um determinado nó da rede possui em outro. Eles são [Jøsang et al. 2006]: beliefe (b) e disbeliefe (d) (crença ou descrença), que são influen- 
ciados por eventos passados provenientes do indivíduo, sendo estes eventos positivos e negativos, onde eventos positivos aumentam a crença e vice-versa; uncertainty $(u)$ (incerteza), grau de incerteza (ou ignorância) que se possui acerca de um evento, este parâmetro diminui conforme o número de observações do indivíduo aumenta; $\alpha$ ou $a$, pode ser considerado como a confiança inicial que se pode ter sobre um novo nó da rede ou como a probabilidade real de acontecimento de um evento, caso este valor seja conhecido. Juntos, os quatro parâmetros formam a opinião de um indivíduo em outro. Os parâmetros $b, d$ e $u$ são calculados como apresentado nas equações 1 [Jøsang 2016].

$$
b=\frac{p}{p+n+k}, d=\frac{n}{p+n+k}, u=\frac{k}{p+n+k} .
$$

As propriedades dos parâmetros estão presentes nas equações 2 e 3 . Note que, para o maior grau possível de incerteza, $u=1$, os valores de $b$ e $d$ são zero e pode-se dizer que é o estado de completa ignorância acerca da ocorrência de um determinado evento. Em contra partida, para o menor grau possível de incerteza $u=0$ sobre um evento, diz-se que a opinião sobre este é dogmática e pode obter este valor após infinitas observações [Jøsang et al. 2006]. Um destaque possível para LS é a existência de um método de cálculo de consenso existente que permite a junção de duas opiniões (conflitantes ou não) sobre um determinado dado [Jøsang 2016].

$$
\begin{gathered}
b, d, u, a \in[0,1] \\
b+d+u=1
\end{gathered}
$$

\section{Proposta}

No presente trabalho é proposto um método para gerenciar a confiança de nós em redes RSSF. Este método deve utilizar RC para qualificar o estado do nó na rede e dos dados provenientes dele. A técnica de LS será utilizada para calcular o grau de confiança de um nó na rede a partir dos dados provenientes dele. Além de identificar anomalias, desejase que para os dados coletados pelos nós seja associado um grau de confiança, que é calculado a partir da ocorrência de eventos (anômalos ou não). Isto faz com que seja possível mensurar a precisão dos dados e, caso necessário, aplicar reparos na rede.

A ideia é que o algoritmo proposto trabalhe em uma arquitetura semi-hierárquica. Desta forma há: "nós receptores", que calculam a confiança de cada um dos "nós sensores" abaixo deles; "nós sensores", que são responsáveis por coletar dados sobre e enviá-los até os "nós receptores"; "nó mestre", que pode ser um ou mais nós, que são efetivamente finais e recebem dados sobre a confiança dos "nós sensores" e os dados coletados, e deve disponibilizar esses dados ou repassá-los para outros nós. Desta forma, o algoritmo deve ser executado nos "nós receptores", para calcular a confiança dos "nós sensores".

O método proposto deve ser executado nos "nós receptores" de dados. Ele também deve ser capaz de executar determinadas ações, porém não necessariamente nesta ordem: receber os dados dos "nós sensores"; classificar dados recebidos como anômalos ou não; gerar uma opinião acerca dos dados recebidos; agregar os dados não anômalos; agregar as opiniões provenientes dos dados; enviar os valores agregados dos dados e das opiniões 
para os nós superiores; enviar o valor anômalo e a opinião deste, caso houver, para os nós superiores.

A etapa "classificar dados recebidos como anômalos ou não" tem como objetivo catalogar os dados de mesma natureza recebidos em um mesmo tempo $t$ em anômalos ou não. Isto deve ser feito utilizando um método computacionalmente simples de DA, preferencialmente estatístico [Ahmed et al. 2016, Zhang et al. 2010]. A ideia é que este processo não necessite de grande poder computacional.

A etapa de "gerar um opinião acerca dos dados recebidos" usa a LS para tal, após eles terem sido passados pela etapa de classificação. Dados considerados anômalos são tratados como eventos negativos, dados considerados não anômalos são tratados como eventos positivos. A partir destes valores serão calculados os valores de belief, disbelief e uncertanty. Como o método não necessita de um treinamento inicial, a opinião inicial escolhida para todos os dados proveniente dos nós sensores e todos os nós é de ignorância.

Após a etapa de classificação, o passo de "agregar os dados não anômalos" agrupa os dados que foram rotulados como não "normais", afim de enviar os valores de forma condensada para o nó superior. Para dados numéricos, de mesma natureza e não anômalos recebidos no mesmo instante de tempo $t$, uma técnica que pode ser utilizada é o envio do valor médio destes dados neste instante $t$.

O processo de "agregar as opiniões proveniente dos dados" utiliza o consenso apresentado em [Jøsang 2016] para condensar a opinião já existente presente no "nó receptor" com a nova opinião, derivada dos novos dados e gerada na etapa "gerar uma opinião acerca dos dados recebidos".

Nas etapas referentes ao "envio de dados" é importante observar que os dados considerados anômalos pela classificação não serão descartados. Este dado destoante é enviado ao "nó receptor" juntamente com a opinião agregada do nó responsável por ele. Isto é relevante pois um dado considerado anômalo em determinado momento pode ser fruto de uma alteração pontual e momentânea do que está sendo monitorado. Desta forma, não há perda de dados, porém há uma condensação dos dados destacando apenas o que é irregular.

\section{Conclusões}

O presente trabalho buscou apresentar um método para medir a confiança em redes de sensores sem fio. Nota-se que o método proposto é genérico o suficiente para ser utilizado em outros tipos de cenários. Como trabalhos futuros buscar-se-á fazer a verificação do modelo proposto, deve ser elaborado um algoritmo que verifique a eficácia do uso de $\mathrm{RC}$ com DA. Testes do algoritmo em ambiente simulado e em ambiente real devem ser executados afim de verificar o comportamento do modelo em rede e o consumo de energia dispensado pelo nó.

A vantagem da utilização de RC juntamente com o processo de DA é agregar memória e incerteza a determinados tipos de dado (como dados de coleta, dados de consumo energético, etc). Com estes valores de memória deve ser possível identificar se um nó teve comportamento considerado anômalo no passado e por quanto tempo, visto que o valor da confiança decai de forma proporcional ao aumento de ocorrências de anomalias.

Espera-se que com o valor de opinião gerado através da LS e utilizando o operador 
de consenso proposto em [Jøsang 2016] seja possível agregar opiniões entre o estado passado e sobre o estado atual do nó. Desta forma, o histórico do tipo de evento passado mais comum é expressado pelo valor da opinião do nó.

\section{References}

Ahmed, M., Mahmood, A. N., and Hu, J. (2016). A survey of network anomaly detection techniques. Journal of Network and Computer Applications, 60:19-31.

de Souza, R. P., Carmo, L. F., and Pirmez, L. (2017). An enhanced bootstrap method to detect possible fraudulent behavior in testing facilities. Accreditation and Quality Assurance, 22(1):21-27.

Dhulipala, V. S. and Karthik, N. (2017). Trust management technique in wireless sensor networks: Challenges and issues for reliable communication: A review. CSI Transactions on ICT, 5(3):281-294.

Gubbi, J., Buyya, R., Marusic, S., and Palaniswami, M. (2013). Internet of things (iot): A vision, architectural elements, and future directions. Future generation computer systems, 29(7):1645-1660.

Guo, J., Chen, R., and Tsai, J. J. (2017). A survey of trust computation models for service management in internet of things systems. Computer Communications, 97:1-14.

Jøsang, A. (2001). A logic for uncertain probabilities. International Journal of Uncertainty, Fuzziness and Knowledge-Based Systems, 9(03):279-311.

Jøsang, A. (2016). Subjective logic. Springer.

Jøsang, A., Hayward, R., and Pope, S. (2006). Trust network analysis with subjective logic. In Proceedings of the 29th Australasian Computer Science Conference-Volume 48, pages 85-94. Australian Computer Society, Inc.

Kaushal, K. and Kaur, T. (2015). A survey on attacks of wsn and their security mechanisms. International Journal of Computer Applications, 118(18).

Khan, Z. A. and Herrmann, P. (2017). A trust based distributed intrusion detection mechanism for internet of things. In Advanced Information Networking and Applications (AINA), 2017 IEEE 31st International Conference on, pages 1169-1176. IEEE.

Sinha, P., Jha, V., Rai, A. K., and Bhushan, B. (2017). Security vulnerabilities, attacks and countermeasures in wireless sensor networks at various layers of osi reference model: A survey. In Signal Processing and Communication (ICSPC), 2017 International Conference on, pages 288-293. IEEE.

Victor, P., Cornelis, C., and De Cock, M. (2011). Trust networks for recommender systems, volume 4. Springer Science \& Business Media.

Xie, M., Han, S., Tian, B., and Parvin, S. (2011). Anomaly detection in wireless sensor networks: A survey. Journal of Network and Computer Applications, 34(4):13021325 .

Zhang, Y., Meratnia, N., and Havinga, P. J. (2010). Outlier detection techniques for wireless sensor networks: A survey. IEEE Communications Surveys and Tutorials, 12(2):159-170. 